\title{
HEMATOMA SUBDURAL EM RECÉM-NASCIDO
}

\author{
ANTonio B. LefÈvRe * \\ Oswaldo R. CRuz **
}

Hematomas subdurais em recém-nascidos são de incidência relativamente freqüente. Ingraham e Matson 1, em 169 casos de hematoma subdural observados em crianças até 2 anos de idade, registraram 25 casos em pacientes com idade inferior a um mês; julgam êstes autores que a freqüência com que o processo é diagnosticado na infância corresponde ao interêsse com que é procurado.

Em geral o diagnóstico dessas lesões é clínico, não se cogitando da confirmação pelos recursos subsidiários; entretanto, se há casos em que os elementos clínicos permitem diagnóstico seguro, em outros os achados clínicos são discretos, deixando dúvidas que tornam imprescindiveis os exames subsidiários. Usualmente a exploração do espaço subdural é indicada mesmo em casos duvidosos, pois os exames de laboratório, inclusive do líqüido céfaloraquidiano são, em geral, negativos ou dão informes pouco precisos. O examc radiológico simples tem limitadas possibilidades na maioria dos casos; em geral não se cogita da indicação dos exames radiológicos contratados, tendo Ingraham e Matson utilizado a pneumencefalografia em apenas um de seus 169 casos para confirmar a hipótese de hematoma subdural e, ainda assim, justificando o emprêgo dêste recurso em vista da ausência de sinais de hipertensão intracraniana.

A nosso ver, nos casos em que a exploração subdural exige a perfuração craniana, outros exames como a eletrencefalografia e a angiografia cerebral devem ser utilizados. O presente trabalho justifica-se por ser êste o primeiro caso de hematoma subdural em recém-nascido observado no Serviço em que trabalhamos, confirmado por documentação eletrencefalográfica e angiográfica.

A. P. A., recém-nascido de 10 dias de idade, branco, sexo masculino, internado em 12-5-1955 (reg. 400.475). Mãe primipara. Parto normal com apresentacão cefálica. Exame clínico-neurológico - Recém-nascido pesando $3.660 \mathrm{~g}$ e com $51 \mathrm{~cm}$ de comprimento; prostrado e sonolento; fontanela tensa e céfalo-hematoma occipital; não chorou durante todo o exame, realizando poucos movimentos espontâneos, particularmente escassos no membro superior díreito; ptose palpebral à esquerda; anisocoria com midriase em $\mathrm{OE}$; hipotonia generalizada, com curtos periodos de hipertomía em extensão ou flexão; reflexos patelares fracos e esgotáveis; ausentes os de-

Trabalho da Clínica Neurológica da Fac. Med. da Univ. de Săo Paulo (Prof. A. Tolosa).

* Livre-Docente; ** Plantonista do Pronto Socorro de Neurocirurgia. 


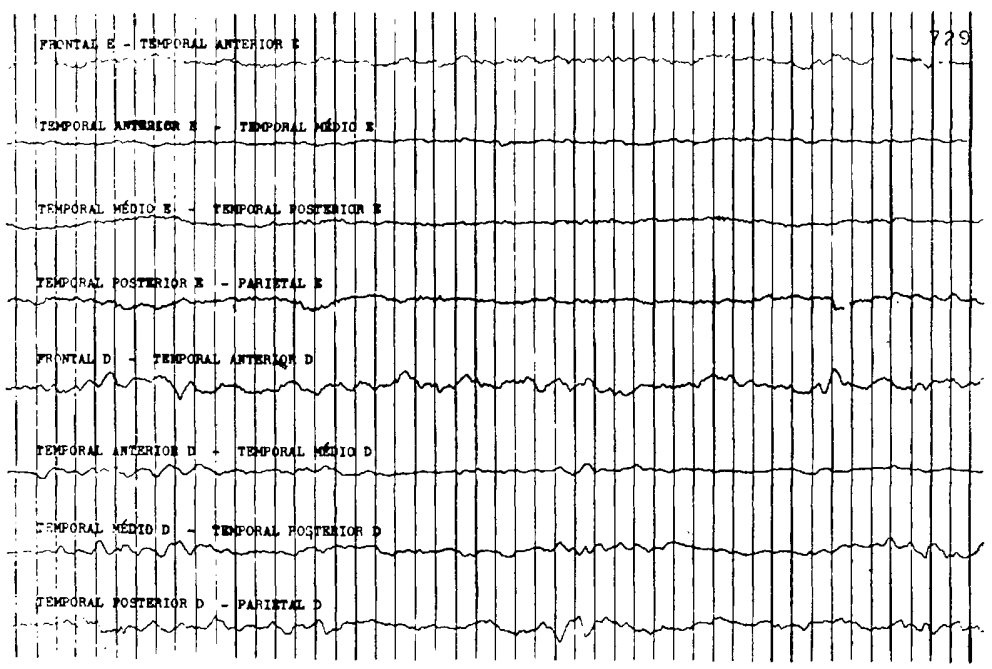

Fig. 1 - Caso A. P. A. Traçado eletrencefalográfico mostrando depressão da atividade elétrica na regiāo temporal esquerda.
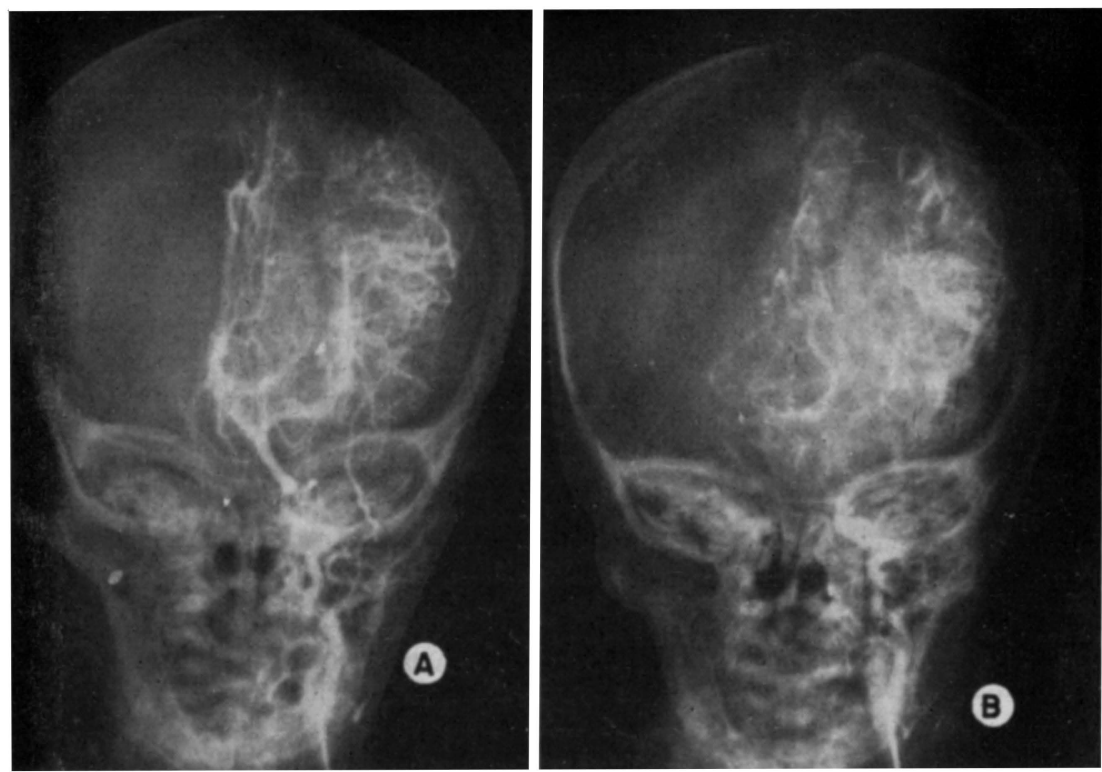

Fig. 2 - Caso A. P. A. Ianto na tase arterial (A), como na tase venosa

(B), nota-se espaço avascular entre o contoorno ósseo e a superfície do hemisfério cerebral. 
mais reflexos profundos; "grasping" discreto, obtido apenas nas māos. Com a hipótese diagnóstica de hematoma no hemicrânio esquerdo, foi pedido exame eletrencéfalográfico que mostrou depressão da atividade elétrica no hemisfério esquerdo, principalmente na região temporal (fig. 1). Angiografia cerebral via artéria carótida esquerda (fig. 2): na fase arterial, em incidência sagital, desvio do grupo silviano e da artéria cerebral anterior para o lado direito, havendo espaço avascular entre o contôrno ósseo e a superfície do hemisfério cerebral delineada pelo contraste; na fase venosa, em incidência sagital, também se observa o espaço avascular, sem, entretanto, haver nitido limite com a superficie do hemisfério cerebral.

Intervençio cirúrgica (16-5-1955) - Mediante perfuração temporal esquerda foi retirada grande quantidade de sangue escuro, contido no espaço subdural. A introdução de sonda fina nesse espaço permitiu a aspiração de pequenos coágulos de sangue junto à corticalidade temporal e à dura-mater. Retirado o hematoma, foi observada a expansão imediata do cérebro que se encontrava afastado cêrca de 2,5 cm da tábua óssea.

No dia imediato à intervenção, a fontanela já não se apresentava tensa; o reflexo de sucção foi obtido; permanecia inalterada a midriase. No $2^{\circ}$ dia do pósoperatório regredira parcialmente a ptose palpebral e monoparesia do membro superior direito. No $12^{\circ}$ dia do pós-operatório êsses distúrbios tinham regredido inteiramente; o reflexo cutâneo-plantar que até essa data se fazia em extensão, passou a dar resposta em flexão, bilateralmente. A alta hospitalar foi dada no $21^{\circ}$ dia do pós-operatório. Nessa ocasião, o exame clinico-neurológico mostrou: assimetria nos movimentos extrínsecos oculares com estrabismos transitórios, variáveis, nāo paraliticos; anisocoria com midriase paralitica no ôlho esquerdo. $O$ paciente foi reexaminado aos 3 meses de idade, apresentando as mesmas alterações da motricidade extrinseca e intrínseca oculares; entretanto não foram assinalados distúrbios motores ou do tonus muscular; atividade reflexa normal para a idade; novo exame eletrencefalográfico, feito nessa ocasião, mostrou depressão da atividade elétrica em área occipital, sendo normal a atividade temporal.

\section{COMENTARIOS}

Neste caso, os elementos obtidos com o exame clínico-neurológico e com o eletrencefałograma já autorizavam a exploração cirúrgica do espaço subdural e, conseqüentemente, uma confirmação imediata da hipótese de hematoma intracraniano. Entretanto, utilizamos a angiografia cerebral tendo em vista que nossa experiência em outros casos mostrara ser êsse exame inócuo, mesmo em recém-nascidos com idade inferior a 10 dias. $O$ tempo venoso em incidência sagital é o que, na maioria dos casos, melhor visibiliza o espaço avascular observado nos hematomas subdurais, segundo recente publicação de Zaclis e Tenuto ${ }^{2}$. Em nosso caso, a maior nitidez da zona avascular foi obtida no tempo arterial, em virtude da fase venosa ainda estar insuficientemente contrastada. Julgamos que isso se explica pela precocidade da fase venosa que, se mais tardia, viria a demonstrar a área avascular tão nítida como tem sido verificado em outros casos no adulto.

Não indicamos a exploração subdural através de uma simples agulha de punção, como preconizam Ingraham e Matson e, sim, a trepanação craniana, por julgarmos que essa via proporciona maiores possibilidades de sondagem e aspiração do espaço subdural. 
Os autores apresentam um caso de hematoma subdural em recém-nascido de 10 dias de idade, cujo principal interêsse reside na documentação mediante eletrencefalografia e angiografia cerebral. O eletrencefalograma revelou depressão da atividade elétrica na região temporal esquerda e a angiografia cerebral mostrou uma área avascular localizada entre a tábua óssea e a superfície do hemisfério cerebral delineado pelo contraste. Baseados na inocuidade dêsse exame, observada em casos de recém-nascidos com menos dias de idade, preconizam os autores a angiografia cerebral nos casos em que o exame clínico não fôr suficiente para o diagnóstico.

\section{SUMMARY}

Subdural hematoma in a newborn.

Case report of subdural hematoma of a newborn ten days old boy whose chief interest consists in the documentation through electrencephalography and cerebral angiography. The EEG showed low voltage electrical activity on left temporal area; carotid angiography showed a nonvascular area located between the bone and the surface of the cercbral hemisphere. Since that in their experience the cerebral angiography is inocuous in cases of newborns younger than 10 days, the authors recommend this procedure in cases in which clinical examinations is not enough for diagnosis.

\section{BIBLIOGRAFIA}

1. INGRAHAM, F. D.; MATSON, D. D. - Subdural hematoma in infancy. Adv. in Pediatrics, 231:4, 1949. 2. ZACLIS, J.; TENUTO, R. A. - Contribuicão para o diagnóstico dos hematomas subdurais. Arq. Neuro-Psiquiat. (São Paulo), 13:273 (dezembro), 1955.

Clínica Neurológica. Hospital das Clínicas da Fac. Med. da Univ. de São Paulo Caixa Postal 3461 - São Paulo, Brasil. 